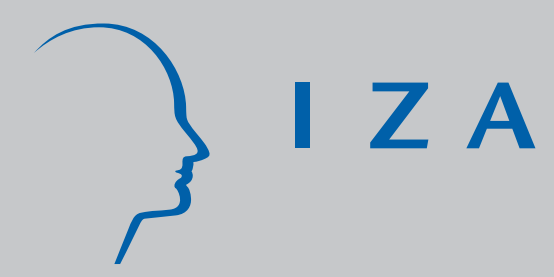

IZA DP No. 1712

Entrepreneurship Among Married

Couples in the United States:

A Simultaneous Probit Approach

Simon C. Parker

August 2005 


\title{
Entrepreneurship Among Married Couples in the United States: A Simultaneous Probit Approach
}

\author{
Simon C. Parker \\ University of Durham \\ and IZA Bonn
}

\section{Discussion Paper No. 1712 \\ August 2005}

\author{
IZA \\ P.O. Box 7240 \\ 53072 Bonn \\ Germany \\ Phone: +49-228-3894-0 \\ Fax: +49-228-3894-180 \\ Email: iza@iza.org
}

\begin{abstract}
Any opinions expressed here are those of the author(s) and not those of the institute. Research disseminated by IZA may include views on policy, but the institute itself takes no institutional policy positions.

The Institute for the Study of Labor (IZA) in Bonn is a local and virtual international research center and a place of communication between science, politics and business. IZA is an independent nonprofit company supported by Deutsche Post World Net. The center is associated with the University of Bonn and offers a stimulating research environment through its research networks, research support, and visitors and doctoral programs. IZA engages in (i) original and internationally competitive research in all fields of labor economics, (ii) development of policy concepts, and (iii) dissemination of research results and concepts to the interested public.
\end{abstract}

IZA Discussion Papers often represent preliminary work and are circulated to encourage discussion. Citation of such a paper should account for its provisional character. A revised version may be available directly from the author. 


\section{ABSTRACT}

\section{Entrepreneurship Among Married Couples in the United States: A Simultaneous Probit Approach*}

This article proposes a simultaneous probit equation framework to analyse the business ownership patterns of married couples in the United States. A structural model of knowledge spillovers within couples is formulated and estimated. Empirical analysis reveals significant and substantial positive interdependence of business ownership propensities within couples. We argue that the evidence is consistent with both male and female spouses receiving positive knowledge transfers from the other. Conversely, there appears to be little support for alternative explanations of interdependent occupational choices based on assortative mating, role model effects, risk diversification, or intrahousehold wealth transfers. We conclude that the conventional practice of ignoring occupational interdependence can generate misleading conclusions about the determinants of business ownership in America.

JEL Classification: J23, J24, M13

Keywords: entrepreneurship, occupational choice, family, business ownership

Corresponding author:

Simon C. Parker

School of Economics, Finance \& Business

23-26 Old Elvet

Durham DH1 3HY

UK

Email: S.C.Parker@durham.ac.uk

\footnotetext{
* The author is grateful to Don Bruce, Rob Fairlie, Armin Falk, Ron Oaxaca, Michael Ransom, and seminar participants at the Tinbergen Institute (Amsterdam), London School of Economics, EALE/SOLE 2005, IZA (Bonn) and University of California at Santa Cruz for numerous helpful comments on an earlier draft. The usual disclaimer applies.
} 


\section{Introduction}

Research into the determinants of entrepreneurship continues to grow, with recent contributions emphasising borrowing constraints (Evans and Jovanovic, 1989; Hurst and Lusardi, 2004); human capital (Lazear, 2002, 2004); geographical location (Acs et al, 2004), and ethnicity (Fairlie and Meyer, 1996; Fairlie, 2004). There is now a rich body of knowledge about the individualspecific factors associated with the decision to be an entrepreneur. The literature has also begun to extend into the domain of the family, reflecting growing recognition of the disproportionate number of married entrepreneurs (Blanchflower and Meyer, 1994; Bates, 1995); parental influence on self-employment choices (Dunn and Holtz-Eakin, 2000); and the growing interest in female entrepreneurship and the role of their husbands (Caputo and Dolinsky, 1998; Bruce, 1999). However, the literature has largely ignored the possibility that an individual's decision to be an entrepreneur might both affect and be affected by the entrepreneurial propensities of their marital partner. This is reflected by the fact that the studies cited above are based on single equation logit or probit models of occupational choice, which invoke strong assumptions about the exogeneity of outside influences on the decision to be an entrepreneur.

The present article shifts the spotlight of economic entrepreneurship research away from the individual and on to the family unit. Building on the observation that couples comprise the majority of business owners in America, we propose a new approach to estimating a family model of entrepreneurship participation for married couples. ${ }^{1}$ At the core of the paper is the notion of knowledge spillovers, which captures the idea that information

\footnotetext{
${ }^{1}$ For example, of the 5303 male household heads of working age in the 2003 wave of the Panel Study of Income Dynamics (PSID), 763 were business owners, of whom 577 (75.6\%) were married.
} 
and knowledge about business ownership and business conditions can be shared easily and efficiently between spouses. ${ }^{2}$ But we also recognise that there might be favourable opportunities for spouses to find complementary occupational mixtures, and embed this possibility into the analysis as well; and we go on to consider the impact of household risk-sharing on diversification or concentration of entrepreneurship within couples. We treat each spouse's occupational choice as endogenous, and derive from a simple theoretical framework an estimable simultaneous equation probit model. This is estimated using Panel Study of Income Dynamics (PSID) data. When interpreting the results, we perform a series of robustness checks in an attempt to distinguish knowledge spillovers from other possible explanations of interdependent occupational choice, including role model effects, intra-household wealth transfers, assortative mating, and risk diversification. The longitudinal dimension of the PSID is used to dig into these alternative explanations.

Confirming the usefulness of analysing entrepreneurship participation at the family level, we find strong evidence of positive interdependence in business ownership, with both male and female entrepreneurs receiving positive spillovers from the other. Furthermore, the effects appear to be substantial in economic terms. Depending on the particular econometric specification used, husbands whose wife is certain of being a business owner have on average a 12-20 percentage point higher probability of being a business owner than if they were married to a woman who was certain not to be a business owner. The corresponding figure for women is 9-14 percentage points. This compares with the unconditional probability of being a business owner in our sample of $13.3 \%$ for men and $6.8 \%$ for women. Spillover effects appear

\footnotetext{
${ }^{2}$ See, e.g., Wong (1986). Spillovers have not been extensively analysed in the context of household decision making or occupational choice, in sharp contrast to other areas of economics including productivity (Moretti, 2004); economic growth (Holod and Reed, 2004); innovation (Sena, 2004) and labour mobility (Berliant et al, 2002).
} 
not only to be large, but also play an important part in explaining patterns of male and female business ownership. We conclude that ignoring interdependence can generate misleading conclusions about the determinants of business ownership in America.

The article is structured as follows. Section 2 sets out a simple modelling framework to analyse interdependent occupational choice. Section 3 derives from it an estimable econometric specification and discusses estimation and identification issues. Section 4 describes the sample data. Section 5 presents and discusses the econometric results. Section 6 concludes.

\section{Model framework}

This section has three parts. The first outlines the notation and assumptions. The second part derives results assuming certainty about future incomes, while the third analyses the effects of introducing risk.

\subsection{Notation and assumptions}

There are $n$ households denoted by $i$, each of which comprises two individuals denoted by $g$ and $g^{\prime}:\left(g, g^{\prime}\right) \in\{1,2\}, g \neq g^{\prime}$. Person $g$ in household $i$ is denoted by $(g, i)$. There is a single time period, in which all incomes are spent on a composite good. Each individual can enter one of two occupations, indexed by $j: j \in\{b, p\}$. Denote $(g, i)$ 's available income in occupation $b$ (business ownership, or 'entrepreneurship') by $y_{g i b}$ and in $p$ by $y_{\text {gip }}$. Incomes in $b$ are stochastic, and relative to those in $p$ attract a random return $\epsilon_{g i}$, with mean $\mu_{g i}$; incomes in $p$ are certain. Initially, we shall suppose that each individual who chooses $b$ observes their own actual or potential $\epsilon_{g i}$, and also their spouse's $\epsilon_{g^{\prime} i}$, at the start of the period - so they make decisions not only simultaneously but also under certainty. This 
assumption will be relaxed below.

To simplify the analysis, we abstract from leisure, assuming that incomes in each occupation are positive if and only if a single unit of labour is supplied. Choices about whether to engage in household or market production are also taken as given, and will not be modelled as endogenous variables. While it would undoubtedly be interesting to relax these assumptions, this would entail numerous complications, which take us beyond the scope of this article.

If and only if both $g$ and $g^{\prime}$ choose $b$, then $g$ receives a spillover $\theta_{g}$ and $g^{\prime}$ receives $\theta_{g^{\prime}}$. (This allows for possible gender differences in the value of spillovers from joint entrepreneurship.) By being an entrepreneur, an individual might make his or her spouse more productive by sharing their business information and experience either in a separate or a joint venture; then $\theta_{g}>0$ in (1) below. Alternatively, an entrepreneur might benefit if their spouse is an employee, in a complementary occupation, e.g., corporate taxation, or as an employee of their company.Then $\theta_{g}<0$ in the following description of $(g, i)$ 's relative occupational incomes:

$$
y_{g i b}-y_{g i p}=\left\{\begin{array}{llll}
\epsilon_{g i} & \text { if } & \left(g^{\prime}, i\right) & \text { chooses } p \\
\epsilon_{g i}+\theta_{g} & \text { if } & \left(g^{\prime}, i\right) & \text { chooses } b
\end{array}\right.
$$

for $g=1,2$. For simplicity we shall for now take $\epsilon_{g i}$ and $\epsilon_{g^{\prime} i}$ to be uncorrelated with each other. Being idiosyncratic, the $\epsilon$ s are unobserved by the econometrician. ${ }^{3}$ For ease of use below, define $\theta:=\theta_{g}+\theta_{g^{\prime}}$ and $\bar{\theta}:=\theta / 2$.

\footnotetext{
${ }^{3}$ The model abstracts from spillovers in occupation $p$. While it could be relaxed, this assumption serves to concentrate attention on interdependence in one occupation relative to the others. Also, it is hard to imagine what a spillover in as broad a category as 'paid employment' might actually be. Separately, the assumption of $\epsilon$ s being unobservable not only seems realistic, but also gives rise below to a simultaneous system of equations
} 
For simplicity, it is assumed that individuals share household income and determine their occupational choices at the same time as their spouse does. For example, $(g, i)$ 's objective is

$$
\max _{j_{g i}} U\left(y_{g i j}+y_{g^{\prime} i j}+I, X_{g i}\right)
$$

taking $\left(g^{\prime}, i\right)$ 's occupational choice (denoted by $j_{g^{\prime} i}$ ) as given; where $I$ is household non-labour income; $X_{g i}$ is a vector of characteristics associated with $(g, i)$ 's preferences; and $U(\cdot)$ is a quasi-concave function. ${ }^{4}$ Notice that this model embodies co-operative behaviour. Alternative approaches are certainly possible, e.g., non-co-operative decision making (Kooreman, 1994), or co-operative bargaining. We will discuss later the implications of alternative specifications for the interpretation of the econometric model.

\subsection{The case of certain returns}

In this section, we analyse the occupational choice decision of married couples under conditions of certainty. We treat the case of positive spillovers explicitly below; the analysis for negative spillovers goes through analogously and will not be repeated. In Section 2.3 we analyse the implications of individuals being uncertain about their stochastic incomes before choosing whether to become an entrepreneur.

It is convenient to move from a specification of relative incomes, as in (1), to one framed in terms of absolute incomes. In the case of positive

whose endogenous variables are latent rather than observed dichotomous variables. This avoids problems of being forced to impose identifying restrictions on a simultaneous equation dummy variable model that effectively remove interdependence from the econometric specification altogether. See Maddala (1983) for a discussion.

${ }^{4}$ Replacing (2) with an alternative preference structure of altruistic but separable utility would not of itself carry any special implications for occupational interdependence. 
spillovers from $b$, i.e., $\theta_{g}, \theta_{g^{\prime}}>0$, we replace (1) with

$$
y_{g i p}=y_{i p}>0 \quad \text { and } \quad y_{g i b}=\left\{\begin{array}{lll}
y_{i p}+\epsilon_{g i} & \text { if }\left(g^{\prime}, i\right) & \text { chooses } p \\
y_{i p}+\epsilon_{g i}+\theta_{g} & \text { if } \quad\left(g^{\prime}, i\right) & \text { chooses } b
\end{array}\right.
$$

The econometrician does not observe the $\epsilon \mathrm{s}$, so let $z_{g i}^{*}$ denote the econometrician's subjective probability that $(g, i)$ will choose $b$ at a given point in time. Because spouses' decisions are made simultaneously rather than sequentially, this probability is determined jointly with the probability of their spouse's decision rather than being conditional on it. Using (2), we have

$$
\begin{aligned}
z_{g i}^{*}= & \operatorname{Pr}\left[\left[U\left(y_{g i b}+y_{g^{\prime} i b}+I, X_{g i}\right)>U\left(y_{g i p}+y_{g^{\prime} i b}+I, X_{g i}\right)\right], j_{g^{\prime} i}=b\right] \\
& +\operatorname{Pr}\left[\left[U\left(y_{g i b}+y_{g^{\prime} i p}+I, X_{g i}\right)>U\left(y_{g i p}+y_{g^{\prime} i p}+I, X_{g i}\right)\right], j_{g^{\prime} i}=p\right] \\
= & z_{g^{\prime} i}^{*}\left\{\operatorname{Pr}\left[U\left[2 y_{i p}+\theta+\epsilon_{g i}+\epsilon_{g^{\prime} i}+I, X_{g i}\right]>U\left(2 y_{i p}+\epsilon_{g^{\prime} i}+I, X_{g i}\right)\right]\right. \\
& \left.-\operatorname{Pr}\left[U\left(2 y_{i p}+\epsilon_{g i}+I, X_{g i}\right)>U\left(2 y_{i p}+I, X_{g i}\right)\right]\right\} \\
& +\operatorname{Pr}\left[U\left(2 y_{i p}+\epsilon_{g i}+I, X_{g i}\right)>U\left(2 y_{i p}+I, X_{g i}\right)\right]
\end{aligned}
$$

Likewise

$$
\begin{aligned}
z_{g^{\prime} i}^{*}= & z_{g i}^{*}\left\{\operatorname{Pr}\left[U\left[2 y_{i p}+\theta+\epsilon_{g^{i}}+\epsilon_{g^{\prime} i}+I, X_{g^{\prime} i}\right]>U\left(2 y_{i p}+\epsilon_{g i}+I, X_{g^{\prime} i}\right)\right]\right. \\
& \left.-\operatorname{Pr}\left[U\left(2 y_{i p}+\epsilon_{g^{\prime} i}+I, X_{g^{\prime} i}\right)>U\left(2 y_{i p}+I, X_{g^{\prime} i}\right)\right]\right\} \\
& +\operatorname{Pr}\left[U\left(2 y_{i p}+\epsilon_{g^{\prime} i}+I, X_{g^{\prime} i}\right)>U\left(2 y_{i p}+I, X_{g^{\prime} i}\right)\right]
\end{aligned}
$$

Eqs. (3) and (4) are the probabilities that $(g, i)$ and $\left(g^{\prime}, i\right)$ choose to be entrepreneurs summed over both possibilities of their spouse being and not being an entrepreneur. They are the econometrician's structural equations 
describing joint occupational choice. One can easily obtain reduced form solutions for these two equations (see Section 3 below).

The positive spillover renders (3) and (4) interdependent. To see this, it is sufficient to examine the (purely illustrative) case when the utility function (2) is separable in its two arguments. Then (3) and (4) become

$$
\begin{aligned}
& z_{1 i}^{*}=\operatorname{Pr}\left[\epsilon_{1 i}>0\right]+\left\{\operatorname{Pr}\left[\theta+\epsilon_{1 i}>0\right]-\operatorname{Pr}\left[\epsilon_{1 i}>0\right]\right\} z_{2 i}^{*} \\
& z_{2 i}^{*}=\operatorname{Pr}\left[\epsilon_{2 i}>0\right]+\left\{\operatorname{Pr}\left[\theta+\epsilon_{2 i}>0\right]-\operatorname{Pr}\left[\epsilon_{2 i}>0\right]\right\} z_{1 i}^{*}
\end{aligned}
$$

where the econometrician's subjective probability distributions of the $\epsilon$ s map each of the $\operatorname{Pr}[\cdot]$ expressions into positive constants (which are increasing in $\left.\mu_{g i}, \mu_{g^{\prime} i}\right)$. With $\theta>0$ it is evident that the two individuals' probabilities of becoming an entrepreneur (i.e., $z_{1 i}^{*}$ and $z_{2 i}^{*}$ ) are positively related. The reason is that the household benefits from a spillover in $b$ only if the other person chooses $b$ as well.

As noted above, the case of negative spillovers can be treated analogously. It is easily shown that $z_{1 i}^{*}$ and $z_{2 i}^{*}$ are negatively related in this case, because a mutually beneficial spillover is only realised if the other person chooses the alternative occupation.

\subsection{Introducing risk}

So far, we have considered the case where individuals know their own and their spouse's stochastic income realisation in $b$ before choosing their occupation. We now relax that assumption, and suppose that individuals face uncertainty about both their own and their spouse's shock. It is tacitly assumed that some kind of cost prevents individuals from switching occupation immediately after $\left(\epsilon_{g i}, \epsilon_{g^{\prime}}\right)$ are revealed, and thereby dodging an 
adverse shock. Individuals are still assumed to know the probability distribution from which the stochastic realisations are drawn. As before, however, the econometrician has incomplete information so once again we will end up with a probabilistic econometric choice model.

The basic ideas below can be illustrated most easily by taking a special parameterisation of the model: $I=\mu_{g i}=\mu_{g^{\prime} i}=0$ with $U$ separable. To reduce notational clutter, we will also drop the $i$ subscript in the remainder of this section. Consider the simple specification

$$
\begin{aligned}
\epsilon_{g^{\prime}} & =\omega_{g^{\prime}} \\
\epsilon_{g} & =\lambda \epsilon_{g^{\prime}}+(1-|\lambda|) \omega_{g} \quad, \quad-1 \leq \lambda \leq 1
\end{aligned}
$$

where $\omega_{g}$ and $\omega_{g^{\prime}}$ are independent mean-zero realisations of some random variables. So if $\lambda=0, \epsilon_{g}$ and $\epsilon_{g^{\prime}}$ are independent (the case considered in the previous section); if $\lambda=1$, there is perfect covariant risk; and if $\lambda=$ -1 , risk is completely diversified provided both individuals choose the risky occupation $b .^{5}$ Below, we will find it useful to assume two-point distributions of $\omega_{g}$ and $\omega_{g^{\prime}}$ to make our point, which both take the value $e>0$ with probability 0.5 and $-e<0$ also with probability 0.5 . The econometrician is ignorant about $e$.

It should be stressed at the outset that, starting from the position of $\lambda=0$, the introduction of risk does not carry any necessary implications for joint participation in entrepreneurship. While risk-averse individuals would obviously be more likely to choose the safe occupation $p$ if risk is introduced, this does not necessarily affect occupational interdependence unless

\footnotetext{
${ }^{5}$ In the case where $\omega_{g}$ and $\omega_{g^{\prime}}$ are draws from independently normally distributed random variables with variances $s_{g}^{2}$ and $s_{g^{\prime}}^{2}$, $\operatorname{Corr}\left(\epsilon_{g}, \epsilon_{g^{\prime}}\right)=\lambda s_{g^{\prime}}^{2} / s_{g}^{2}$. So if spouses obtain independent draws from the same random variable, $\lambda$ fully describes the correlation of income shocks.
} 
spouses match by risk attitude. The possibility of matching on unobservable characteristics is an empirical issue that we shall return to later.

To see the effect of covariant risk most starkly, consider the case where $\lambda=1$. Then (3) becomes

$$
\begin{gathered}
z_{g}^{*}=z_{g^{\prime}}^{*} \operatorname{Pr}\left\{U\left[2\left(y_{p}+e\right)+\theta\right]+U\left[2\left(y_{p}-e\right)+\theta\right]\right. \\
\left.>U\left[2 y_{p}+e\right]+U\left[2 y_{p}-e\right]\right\}
\end{gathered}
$$

By inspection, if $e=0$ (no risk) and $\theta>0$ then $z_{g}^{*}=z_{g^{\prime}}^{*}$; while $\lim _{e \rightarrow \infty} z_{g}^{*}=$ 0 irrespective of $z_{g^{\prime}}^{*}{ }^{6}$ Hence covariant risk implies a weaker relationship between $z_{1}^{*}$ and $z_{2}^{*}$ of (5) and (6) than in the case of no risk analysed earlier, eroding the effect of any positive spillovers.

If on the other hand risk is diversifying, a case which is illustrated most clearly by $\lambda=-1$, then income risk from one spouse is completely offset by the other if both choose $b$ (but not otherwise). Now if $\theta \geq 0$ we have

$$
\begin{aligned}
z_{g}^{*} & =z_{g^{\prime}}^{*} \operatorname{Pr}\left\{U\left(2 y_{p}+\theta\right)>U\left(2 y_{p}+\epsilon_{g^{\prime}}\right)\right\} \\
& =z_{g^{\prime}}^{*}
\end{aligned}
$$

In this case, each individual chooses the same occupation as their spouse, and thereby diversifies risk completely at the household level. ${ }^{7}$ Hence diversifying risk implies a stronger relationship between $z_{1}^{*}$ and $z_{2}^{*}$ than in the case of no risk analysed earlier, reinforcing the effects of any positive interdependence in entrepreneurship caused by positive spillovers. $^{8}$

\footnotetext{
${ }^{6}$ Of course, if $\theta<0$ then there is no benefit from taking on covariant risk for a negative benefit, so $z_{g}^{*}=z_{g^{\prime}}^{*}=0$.

${ }^{7}$ If $\theta<0, b$ might still be preferred to $p$ if agents are risk averse; $\theta$ can be interpreted as an insurance premium in this case.

${ }^{8}$ Obviously, the logic behind these results continues to apply for intermediate non-zero values of $\lambda$. Note that if occupation $p$ is also risky, the effects on occupational choices become more complicated, depending in addition on how income variability in $p$ is related
} 
In summary, covariant risk counteracts any positive interdependence in entrepreneurship arising from positive spillovers, while diversifying risk has the opposite effect. If risk and risk attitudes are not controlled for, spillover and risk effects may be partly bundled together, raising an important identification issue. It is commonly argued that business owners are especially prone to covariant risks (e.g., Rosenzweig and Stark, 1989; Carter, 1997). If covariant risk is salient, it follows that any positive interdependence in business ownership may understate the true scale of positive spillovers. Then it may be reasonable to treat estimates of interdependence in entrepreneurship as a lower bound on the true role of spillovers; but we will include controls for risk and risk aversion in our econometric specification derived below, in an attempt to obtain sharper estimates of the spillovers themselves.

\section{An econometric specification}

In this section we propose an empirical counterpart to the structural equations of entrepreneurial choice established in the previous section. We then discuss some estimation issues before considering possible ways of identifying knowledge spillovers from alternative explanations of interdependent entrepreneurship.

\subsection{Deriving the empirical model}

To derive an empirical counterpart to the theoretical framework just described, we propose the following specifications of productivity in entrepre-

to that in $b$, as well as the occupation-specific $\lambda$ values. Arguably, this issue is attenuated if a business owner/non-business owner classification is used, as in our empirical application, because if employers smooth employees' wages, one can then more plausibly ignore risk in $p$. 
neurship and household preferences:

$$
\begin{aligned}
\mu_{g i} & =W_{g i}^{\prime} \Upsilon_{g} \\
\epsilon_{g i} & =\mu_{g i}+\nu_{g i} \quad, \quad \nu_{g i} \sim \mathcal{U}\left[-d_{g}, d_{g}\right] \quad \Rightarrow \quad E\left(\nu_{g i}\right)=0 \forall g, i(11) \\
U & =U\left(y_{g i j}+y_{g^{\prime} i j}+I+X_{g i}^{\prime} \zeta_{g j}\right)
\end{aligned}
$$

where $\Upsilon_{g}, \zeta_{g j}$ and $d_{g}>0$ are parameters. Eq. (10) specifies an individual's expected income in entrepreneurship relative to income in paid employment to be a linear function of a set of individual- and gender-specific variables, $W_{g i}$. The impact of these variables might vary systematically by gender (hence the $g$ subscript on $\Upsilon_{g}$ ), because females are observed to have a different structure of returns in entrepreneurship than males (Parker, 2004; van Praag, 2005). Eq. (11) defines a set of mean-zero uniformly distributed random shocks $\nu_{g i}$ that are observed by members of each household $i$ but not by the econometrician. The form in (11) incorporates gender differences in the distribution of shocks, to permit gender-specific income risk in business ownership. ${ }^{9}$ And (12) specifies a tractable non-separable functional form for the utility function, in which pecuniary returns and non-pecuniary individual- and gender-specific covariates $X_{g i}$ affect utility via the parameter vector $\zeta_{g j} .{ }^{10}$ The occupation subscript on $\zeta_{g j}$ allows the effects of some characteristics to impact more on preferences in some occupations than in others. This respects previous empirical findings which suggest that un-

\footnotetext{
${ }^{9}$ The uniform distribution is chosen because it has a tractable cumulative distribution function, enabling estimating equations to be derived directly. Obviously, an alternative distribution could also proposed, e.g., the lognormal; but we can regard the uniform as giving a linear approximation to a non-linear c.d.f entailed by an alternative distributional assumption.

${ }^{10}$ While (12) is of course not completely general, it is both tractable and allows for more general results than (a) assuming 'representative agents' (whereby $\zeta_{g j}=0$ ), or (b) imposing separability, or (c) specifying the curvature of $U(\cdot)$. Evidently, one can propose other non-separable utility functions in place of (12): these would however inevitably induce unwieldy non-linearity into the econometric specification for questionable benefit.
} 
observed preferences are needed to help explain rates of participation in entrepreneurship among some ethnic groups. ${ }^{11}$

Substituting these specifications into (3) and (4) (or equivalently their counterparts for $\theta<0$ ) yields in either case the estimable system

$$
\begin{aligned}
& z_{1 i}^{*}=\alpha_{1}+\Omega_{1 i}^{\prime} \beta_{1}+\gamma_{1} z_{2 i}^{*}+u_{1 i} \\
& z_{2 i}^{*}=\alpha_{2}+\Omega_{2 i}^{\prime} \beta_{2}+\gamma_{2} z_{1 i}^{*}+u_{2 i}
\end{aligned}
$$

where

$\alpha_{g}:=1-\frac{1}{d_{g}} \quad \Omega_{g i}^{\prime} \beta_{g}:=\frac{W_{g i}^{\prime} \Upsilon_{g}+X_{g i}^{\prime}\left(\zeta_{g s}-\zeta_{g p}\right)}{2 d_{g}} \quad \gamma_{g}:=\frac{\bar{\theta}}{d_{g}} \quad g=1,2$

and where $u_{1 i}$ and $u_{2 i}$ are exchangeable gaussian error terms, to capture the possibility of measurement error. Note the testable restriction $\operatorname{sgn}\left(\gamma_{1}\right)=$ $\operatorname{sgn}\left(\gamma_{2}\right)=\operatorname{sgn}(\theta)$. The model given as (13) and (14) is a simultaneous equation probit model. It is internally consistent and estimable under standard identification assumptions described in Section 3.2 below. ${ }^{12}$

In the context of married (employee) couples' work hours, Lundberg (1988) asserted that a simultaneous structure like (13) and (14) nests within it several behavioural models, including joint utility, exogenous spouse choice, and co-operative bargaining models. Applying the same logic here, one might associate the case where $\gamma_{1}$ and $\gamma_{2}$ are both significantly different from zero with joint utility or co-operative bargaining models; and the case where at least one of $\gamma_{1}$ or $\gamma_{2}$ equals zero with exogenous spouse choice. The

\footnotetext{
${ }^{11}$ See Fairlie and Meyer (1996) and Fairlie (2004). We observe that adding (7) and (8) to the specification (10)-(12) for general $\lambda$ does not alter the form of the econometric specification derived below; so that specification appears to be applicable irrespective of the type of risk faced by entrepreneurs.

${ }^{12}$ In contrast, a version of the model where dummy variables appear in place of the latent endogenous variables is not internally consistent (see Kooreman, 1994).
} 
latter case has been the norm in the empirical entrepreneurship literature to date. ${ }^{13}$

To obtain the reduced form of the model associated with (13) and (14), decompose $\Omega_{1}$ and $\Omega_{2}$ into sub-vectors of variables shared by both arrays (denoted by $\Xi$ ); and those found only in $\Omega_{1}$ (namely, $\Lambda_{1}$ ) or $\Omega_{2}$ (namely, $\left.\Lambda_{2}\right)$. That is, $\Omega_{1} \equiv\left[\Xi, \Lambda_{1}\right]$ and $\Omega_{2} \equiv\left[\Xi, \Lambda_{2}\right]$, with parameter vectors $\beta_{1} \equiv$ $\left[\beta_{1 \xi}, \beta_{1 \perp}\right]$ and $\beta_{2} \equiv\left[\beta_{2 \xi}, \beta_{2 \perp}\right]$. Then the reduced form for the model is

$$
\begin{aligned}
z_{1 i}^{*}= & \frac{\left(\alpha_{1}+\gamma_{1} \alpha_{2}\right)+\Xi_{i}^{\prime}\left(\beta_{1 \xi}+\gamma_{1} \beta_{2 \xi}\right)+\Lambda_{1 i}^{\prime} \beta_{1 \perp}+\Lambda_{2 i}^{\prime}\left(\gamma_{1} \beta_{2 \perp}\right)}{1-\gamma_{1} \gamma_{2}} \\
& +u_{1 i}^{*} \\
= & V_{i}^{\prime} \Pi_{1}+u_{1 i}^{*} \\
z_{2 i}^{*}= & \frac{\left(\alpha_{2}+\gamma_{2} \alpha_{1}\right)+\Xi_{i}^{\prime}\left(\beta_{2 \xi}+\gamma_{2} \beta_{1 \xi}\right)+\Lambda_{2 i}^{\prime} \beta_{2 \perp}+\Lambda_{1 i}^{\prime}\left(\gamma_{2} \beta_{1 \perp}\right)}{1-\gamma_{1} \gamma_{2}} \\
& \quad+u_{2 i}^{*} \\
= & V_{i}^{\prime} \Pi_{2}+u_{2 i}^{*}
\end{aligned}
$$

where

$$
u_{1 i}^{*}:=\frac{u_{1 i}+\gamma_{1} u_{2 i}}{1-\gamma_{1} \gamma_{2}} \quad \text { and } \quad u_{2 i}^{*}:=\frac{u_{2 i}+\gamma_{2} u_{1 i}}{1-\gamma_{1} \gamma_{2}}
$$

and $V_{i}:=\left[\mathbf{1}, \Xi_{i}, \Lambda_{1 i}, \Lambda_{2 i}\right]$. Note that the econometrician only observes the indicator variables $z_{1 i}$ and $z_{2 i}$, where $z_{1 i}=1$ if $z_{1 i}^{*} \geq 0.5$ and $=0$ otherwise, with $z_{2 i}$ defined likewise. ${ }^{14}$

\footnotetext{
${ }^{13}$ While significance tests on $\gamma_{1}$ and $\gamma_{2}$ can clearly distinguish the exogenous case from the other two cases of joint utility and household bargaining, further assumptions on $d_{g}$ and $d_{g^{\prime}}$ are needed to distinguish between these latter two cases. For example, if $d_{g}=d_{g^{\prime}}$, then the testable restriction of the joint utility model is $\gamma_{1}=\gamma_{2}$. This kind of restriction is not implied by the bargaining model, in which gender differences in bargaining power enables $\gamma_{1} \neq \gamma_{2}$ (see Lundberg, 1988). But if $d_{1}>d_{2}$ then $\gamma_{1}<\gamma_{2}$ and conversely: so if men have more variable business incomes than women, then male choices will appear to be less affected by female ones than female choices are by male ones. The logic is akin to a 'signal-to-noise' argument: as the noise (stochastic) element increases, it drowns out the signal (spillover).

${ }^{14}$ The threshold of 0.5 is arbitrary, but is the usual empirical cut-off used in the estimation of probit models. The presence of an intercept ensures that it makes no practical
} 
The coefficients of central interest in these specifications are $\gamma_{1}$ and $\gamma_{2}$, because they capture interdependent entrepreneurial choices which are predicted to arise in the presence of knowledge spillovers. Our conceptual framework suggested that the signs of these coefficients reflect whether knowledge spillovers are confined within entrepreneurship (in which case they should be positive); or require complementary occupations to become manifest (in which case they should be negative). And, in the absence of suitable empirical controls for risk, the impact on $\gamma_{1}$ and $\gamma_{2}$ depends on whether risk is covariant or diversifying. Naturally, $\gamma$ estimates of zero imply that any knowledge spillovers are either irrelevant (perhaps because of exogenous rather than joint spouse decision-making), or are completely offset by risk effects. In either case, one can treat entrepreneurial choices of spouses as effectively independent of each other. ${ }^{15}$

We note in passing that ignoring interdependence in entrepreneurial choices when it is actually present, i.e., taking the 'conventional' course of interpreting the coefficients in single equation estimations of (16) and (18) as structural rather than reduced form parameters, could generate misleading inferences. This warning is of practical relevance because most empirical studies of business ownership do precisely this. To see how misleading this can be, suppose that $\gamma_{1} \gamma_{2}>1$ (an empirically relevant case, as shown below). Then by inspection of (15) and (17), the structural and reduced form parameters could take systematically opposite signs, leading to precisely the wrong interpretations.

\footnotetext{
difference where within the (closed) unit interval the threshold is set.

${ }^{15}$ This includes the case where spillovers received by women are equal and opposite to those received by men: $\theta_{g}=-\theta_{g^{\prime}}$, for then $\theta=\bar{\theta}=0$. In a joint utility model only the combined spillover matters; this is why its gender-specific components are not identified in the empirical specification (though see the discussion in footnote 14 above with respect to household bargaining models).
} 


\subsection{Estimation issues}

There are two principal ways of estimating the simultaneous probit model (13) and (14). One is to use a consistent two-step estimator (2SE) proposed by Maddala (1983, Chap. 8.8); the other is to use full information maximum likelihood (FIML).

The 2SE estimator involves estimating the reduced forms (16) and (18) by single equation probit ML at the first stage. This generates 'predicted latent values' of entrepreneurial choices based on the first stage estimates. The second stage then includes these predicted latent values in place of $z_{2 i}^{*}$ and $z_{1 i}^{*}$ in the structural equations (13) and (14). Estimation of the latter by ML generates consistent estimates of all of the parameters, but requires a correction to the parameter variance-covariance matrix owing to the use of 'generated regressors'. ${ }^{16}$ Identifying assumptions for this model are that there is at least one member of $\Omega_{1}$ that does not belong to $\Omega_{2}$ and vice-versa (i.e., neither $\Lambda_{1}$ nor $\Lambda_{2}$ are null vectors). We describe below the particular restrictions used in our empirical application. As usual, the probit structure of (13) and (14) identifies parameters only up to a scalar transformation. So we normalise the variances of $u_{1 i}$ and $u_{2 i}$ to unity at the outset in the normal way.

The 2SE is our favoured estimator owing to its ease of use and robustness relative to FIML. ${ }^{17}$ However, we will report some limited estimates based on FIML because it facilitates estimation of the correlation coefficient between the disturbances, which will be of independent interest (see below). The Appendix derives the likelihood function for this problem.

\footnotetext{
${ }^{16}$ The requisite correction is described in Maddala (1983, pp. 246-47); it was programmed in Version 8.0 of LIMDEP.

${ }^{17}$ FIML estimates are known to be sensitive to: departures from normality of the disturbance terms; uneven likelihood surfaces; and the problem that mis-specification in one equation contaminates all of the other equations in the system.
} 
One econometric possibility that we do not investigate below is estimation of a fixed effects panel version of the system (13) and (14) (or (16) and (18)). Just as the presence of individual fixed effects prevents identification of temporally static covariates, so it eliminates from samples estimated by logit or probit all individuals who do not change occupational status over the sample period - including the numerous interesting cases of 'survivors' who remain in business. This is inconsistent with the frame of reference of our theoretical analysis and the purpose of the present paper. As we now go on to explain, we will instead exploit the longitudinal nature of our data set in an effort to disentangle knowledge spillovers from other possible sources of interdependent entrepreneurial choices.

\subsection{Disentangling spillovers from other sources of interde- pendence}

As noted earlier, knowledge spillovers might not be the only possible explanation for non-zero $\gamma_{1}$ and $\gamma_{2}$ values. We now consider several alternative explanations, and suggest ways of identifying them in the empirical work in an effort to isolate spillover effects.

One alternative explanation is assortative mating. The idea here is that individuals with similar unobserved tastes for entrepreneurship marry each other and then become entrepreneurs, leading to a spurious association between $z_{1}^{*}$ and $z_{2}^{*}$. We test this possibility in two ways. First, unobserved tastes for entrepreneurship that are shared by spouses implies positive correlation between $u_{1}$ and $u_{2}$ in (13) and (14). This can be tested using a FIML estimator. Second, we dig into past waves of the data to explore a theme emerging from assortative mating research that links marriage outcomes to

earlier shared work environments (see, e.g., Kalmijn and Flap, 2001). This 
research suggests that individuals with similar preferences often perform similar work and meet in the same or similar workplaces or occupations. If this phenomenon is relevant for explaining joint entrepreneurship, then at least as many entrepreneur couples should be found working in the same occupations and industries before marriage as are observed there afterwards (see also Nakosteen et al, 2004, for a similar approach). This proposition can be tested directly using previous waves of PSID data. ${ }^{18}$ And, reflecting the fact that couples tend to match on the basis of education, we will also control below for spouse's education on an individual's decision to be an entrepreneur (see Wong, 1986).

A second alternative explanation is role model, or demonstration, effects. If role models are important, individuals might emulate or eschew the occupational choice of their spouse, depending on whether a favourable or unfavourable role model is conveyed. This could cause such choices to covary even in the absence of knowledge spillovers. We distinguish role model effects from knowledge transfers by testing whether one's choice to be an entrepreneur is influenced by one's spouse's record of success in entrepreneurship. Reflecting data limitations in the PSID, we measure success in entrepreneurship as the length of the spouse's most recent continuous spell as a business owner. ${ }^{19}$ We compute a variable of this kind for both spouses

\footnotetext{
${ }^{18}$ A complication arises if women perceive business ownership to be a 'masculine' occupation that penalises them in the marriage market (Badgett and Folbre, 2003). Then relatively few women will become entrepreneurs, leaving the set of observed married couples to be dominated by male entrepreneurs and female employees. This unobserved effect would impart downward bias to estimates of $\gamma_{1}$, though it should presumably leave estimates of $\gamma_{2}$ unbiased. We were unable to think of any ready proxy for this particular unobserved effect.

${ }^{19}$ Including spells up to and including the 2003 wave. The computation of this variable necessitated the calculation of work histories from previous waves of the PSID for every individual in the sample. We did not attempt to weight spells according to when they occurred; so, for example, a spell taking place between 1988 and 1995 was considered equivalent to one occurring between 1996 and 2003. We do not anticipate that our results will change if a weighting scheme is applied to the data.
} 
using previous waves of the PSID. It is denoted the 'Role model' variable hereafter. The impact of 'Role model' on the choice of entrepreneurship will be positive if role models are favourable on average, and will be negative if the opposite is true. ${ }^{20}$ In any event, if knowledge spillovers are important, then $\gamma_{1}$ and $\gamma_{2}$ should remain statistically significant. ${ }^{21}$

A third alternative explanation of positive interdependence in entrepreneurial choices is that it might simply reflect the ability of wealthy individuals to finance their spouses, for example by enabling them to overcome borrowing constraints. Evans and Jovanovic (1989) first showed that borrowing constraints can give rise to a positive relationship between entrepreneurship and wealth. If wealth transfers are important but knowledge spillovers are not, then family wealth should have positive effects on business ownership propensities and should render $\gamma_{1}$ and $\gamma_{2}$ statistically insignificant. In fact, borrowing constraints are not the only reason why greater wealth might increase the probability of business ownership. Another is skill transfers, if wealth serves as a measure of success and hence the capability to transfer useful knowledge (Dunn and Holtz-Eakin, 2000). Alternatively, greater wealth might reduce household risk and/or risk aversion. But if wealth turns out to be insignificant, then none of these explanations will receive support.

Fourth, as discussed in Section 2.3 above, spouses might co-ordinate occupational choices in order to diversify risk. The 'raw' $\gamma_{1}$ and $\gamma_{2}$ estimates would then embody both spillover and risk effects. In an attempt to separate these factors, we will investigate the effects of an additional control variable:

\footnotetext{
${ }^{20}$ Evidence points to adverse effects of business ownership on family life - see, e.g., Williams (2003) and Blanchflower (2004).

${ }^{21}$ Another interpretation proposed by Dunn and Holtz-Eakin (2000) is that parental success in self-employment might be less a demonstration effect than an indicator of potential for skill transfers. If this interpretation is valid for couples as well, then the Role model (i.e., success) variable should have a strictly positive effect on individuals' choices to be entrepreneurs. We test, and reject, this alternative interpretation below.
} 
the dummy variable 'Same industry', which takes the value of one if both members of a couple are located in the same 3-digit industry, and zero otherwise. If risk is industry-specific, then spouses who work in the same industry will be more vulnerable to covariant risk. As a further check, we will also utilise some limited information on risk attitudes in the data set to see if risk aversion is a salient issue anyway.

Finally, we acknowledge the possibility that, by enabling spouses to work alongside each other in the same enterprise, partnerships might be a particularly efficient organisational form for transmitting knowledge spillovers. We will test for this possibility by checking the impact of partnership organisation.

\section{Data and variables}

\subsection{Data selection and dependent variables}

The data for this study are taken from the PSID. The econometric analysis focuses on the most recent wave, 2003; earlier years of the panel were used to explore competing explanations of joint participation in entrepreneurship discussed above. Our sample comprises married working adults aged between 18 and 65, who were not working in agriculture. Our working definition of entrepreneurship is taken to be business ownership, so cases were partitioned into business owner and non-business owner categories. The business ownership classification is used because it recognises that entrepreneurs both create and operate business organisations; this classification is also easy to apply, and has been used in several previous studies (e.g., Cagetti and De Nardi, 2001; Gentry and Hubbard, 2001; and Hurst and Lusardi, 2004). Specifically, we utilise responses from the PSID questions 
that ask "Did you (or anyone else in the family) own a business or have a financial interest in any business enterprise?" After that, respondents are asked about the type of business, who in the family owned it, and whether the owner or spouse worked in the business. The PSID does not define partnerships, so we were obliged to propose our own definition. We defined a couple as a partnership if both spouses worked in and also had part ownership of the same business. The stipulation of working in the business was designed to remove 'sleeping partners' motivated purely by tax shelter considerations. ${ }^{22}$ Further to the impact of income taxation, we observe that the US system of joint taxation removes any incentive for business owner spouses to choose particular occupations in order to minimise tax liabilities: see Schuetze (2004).

In total, 659 ( $13.3 \%$ of) male and 337 (6.8\% of) female respondents were classified as business owners. Of these, 92 cases $(=14.0 \%$ of the 659 men and $27.3 \%$ of the 337 females) were in partnerships with their spouses. In terms of self-employment, $12.3 \%$ of men and $8.4 \%$ of women in the sample were self-employed in their main job. There is incomplete overlap between the business ownership and self-employment classifications: only $70.0 \%$ and $54.9 \%$ of male and female business owners respectively were self-employed. Of the $30.0 \%$ of men who were business owners but not self-employed, $70.1 \%$ owned incorporated businesses, and so were classified as employees in their main job. The corresponding figure for women was $57.2 \% .{ }^{23}$ The remaining

\footnotetext{
${ }^{22}$ Of course, it is possible that some respondents classified themselves inaccurately, e.g., some spouses of business owners who worked informally for the business recorded themselves as inactive or working in paid employment. Alternative classifications such as selfemployment status are also likely to be vulnerable to this problem (as are self-reported work hours). However, we believe that by giving respondents the opportunity to report work involvement separately from ownership, the PSID might reduce the scale of this problem. To the extent that it persists, mis-classification will have ambiguous effects on the interdependence of entrepreneurial choices, depending on whether the problem is greatest among business owners or employees.

${ }^{23}$ Every individual with an incorporated business was a business owner.
} 
non-self-employed business owners tended to be employees in their main job, who worked in their business on a part-time basis. The incidence of this was higher among women than among men.

The empirical ambiguities and 'grey areas' arising from self-employment classifications are well known (see Dennis, 1996). For this reason we will mainly report results for business ownership, and will interpret supplementary results based on the self-employment classification with particular caution.

\subsection{Explanatory variables}

As noted in Section 3.1 above, both preferences and variables that affect relative occupational incomes are likely to affect the business ownership decision. To capture these influences, we followed previous researchers by including in the covariate vectors $\Omega_{1}$ and $\Omega_{2}$ (orthogonal polynomials of) age and age squared, ${ }^{24}$ and dummy variables for whether the highest level of educational attainment was high school graduation or a completed college degree. To the extent that these variables measure human capital, they might either increase the likelihood of business ownership or reduce it, depending on how they affect returns in business ownership relative to those in paid employment (van Praag, 2005). Previous evidence has generally found participation rates in entrepreneurship to increase with age up to a maximum, before declining in later years; the results for own education levels are more mixed, though they have generally been found to be negative in the United States (Blanchflower, 2004). Other research has identified a positive influence on income from one's spouse's education, which appears to be more pronounced for entrepreneurs than for workers (Wong, 1986).

\footnotetext{
${ }^{24}$ Orthogonal polynomials were used as raw age and its square were highly collinear.
} 
This might capture another conduit for knowledge spillovers, with more educated individuals being able to usefully advise their spouses in business. We also control for this possibility below. ${ }^{25}$ And, to control for influences from family background, we also include dummies for high school educational attainment of parents, separately for mothers and fathers. ${ }^{26}$

Previous research clearly shows that blacks and Latinos experience lower unconditional rates of business ownership and self-employment in the United States (see, e.g., Fairlie, 2004). As well as including dummy variables for ethnicity, we also control for broad regional location (Southern, North Central and North East) and urban density, where we define a location with a 'high' urban density as one with more than one million people; and a 'medium' urban density as one containing between a quarter and one million people. Previous research has found mixed effects for population density on business ownership and firm formation rates (c.f. Brock and Evans, 1986, and Reynolds et al, 1994). And, following some previous researchers who report an impact of health on self-employment propensities (Fuchs, 1982; Borjas, 1986; Rees and Shah, 1986; Gill, 1988), we also include dummy variables coded to one if individuals and their spouses report that they suffer from poor health. Finally, we control for a range of family factors, including the number of children in the household and the number of children under six years old. Supporting children might increase the necessity both of lucrative work and of flexible job schedules, while infants under 6 years old may constrain the ability of parents to work regular hours. These factors have been found by some previous researchers, for example, to help explain female business ownership patterns (Macpherson, 1988; Caputo and Dolin-

\footnotetext{
${ }^{25}$ In contrast, spouse's age (as a measure of experience) does not appear to play this role: see Wong (1986).

${ }^{26}$ Unfortunately, information about parental self-employment experience is absent from the PSID.
} 
sky, 1998; Bruce, 1999; and Lombard, 2001; but see also Taniguchi, 2002). We also include variables measuring the average weekly hours spent doing housework of each individual and their spouse. Previous studies show that women tend to do more housework than men on average (Hundley, 2001; Edwards and Field-Hendrey, 2002).

Identifying restrictions are suggested by the likelihood that — once occupational interdependence is taken into account - a woman's age (and its square), her father's and mother's education, and her ethnicity will affect her occupational choice but not that of her husband (and likewise for men). In addition, reflecting widespread evidence that the presence of children in the household affects female more than male attitudes to work, this variable and the age of the youngest child are excluded from the male specification. ${ }^{27}$

Summary statistics of the variables used in the study are collected in Table 1. ${ }^{28}$ Consistent with previous evidence (e.g., Parker, 2004, Chap. 3), business owners tend on average to be older, slightly better educated, and from families where the father was more likely to be a college graduate. They are also more likely to be white and live as owner-occupiers in less densely populated areas than non-business owners. ${ }^{29}$ A third of male business owners had wives who were also business owners, while 51 per cent

\footnotetext{
${ }^{27}$ Likelihood ratio tests yielded $\chi^{2}(8)=12.712$ for men and $\chi^{2}(6)=4.496$ for women, so we were unable to reject these over-identifying restrictions. Checks also revealed that the estimates of $\gamma_{1}$ and $\gamma_{2}$ given below were insensitive to these restrictions.

${ }^{28}$ All statistics are based on unweighted data, as it is unclear how our reduced sample of married couples could be re-weighted to make it nationally representative. Neither do we include Heckman selectivity terms, since we do not attempt to generalise our findings beyond working married couples; were we to do so we would face the practical impediment of finding appropriate identifying instruments. In this context it is noteworthy that the only study we know of that attempts this (Macpherson, 1988) found insignificant participation selection effects for self-employment choices of American women.

${ }^{29}$ The low business ownership rate of Latinos is striking. Two possible reasons are the exclusion of agricultural families from the sample, and under-representation in the PSID of newer waves of Latino immigrants. The latter problem has been recognised and partly addressed by the PSID in a special supplemental Latino sample; but these individuals do not form part of the core PSID. I am grateful to Rob Fairlie for discussions on these issues.
} 
of female business owners had husbands who were business owners. These figures might appear high in view of the health insurance benefit to business owners of having an employed spouse who can include them in their company insurance cover (Perry and Rosen, 2004). In fact, self-employed Americans have been able to deduct health premiums from their business expenses (in their entirety since 2003); this attenuates the health insurance advantage of having an employed as opposed to a business owner spouse.

\section{Results}

Before presenting the results from estimating (13) and (14), for comparative purposes we briefly summarise results from a benchmark case without interdependent business ownership, i.e., for the case where $\gamma_{1}=\gamma_{2}=0$ is imposed at the outset. It turned out that the results for this case were broadly similar to those reported by previous researchers. For men, business ownership propensities were found to be increasing but concave in age, and significantly lower for blacks, Latinos, and respondents in relatively poor health. Among women, blacks and Latinos were again significantly less likely to be business owners, as were older respondents in poor health and high-school graduates. Women with children located in rural areas outside the South were significantly more likely to be business owners than the average woman.

Columns I of Table 2 presents the results from estimating (13) and (14) by Maddala's two-step estimator. The table reveals substantial positive occupational interdependence, with both husbands and wives being significantly more likely to own a business if their spouse does too. This is consistent with the notion of positive occupational spillovers although, as noted above, other interpretations are also possible which we go on to explore 
below. While females appear to benefit a little more from interdependence than males do, the gender difference in the $\gamma \mathrm{s}$ is relatively modest. The marginal effects corresponding to the $\gamma_{1}$ and $\gamma_{2}$ estimates are 0.12 and $0.09 .{ }^{30}$ This means, for example, that if a man's wife is certain of being a business owner, this will increase the probability that the man will become a business owner by 12 percentage points relative to the case where the wife is certain not to be a business owner. These are relatively large effects compared with the unconditional sample probabilities of business ownership of $13.3 \%$ for men and $6.8 \%$ for women.

A few other covariates are significantly associated with business ownership, including own college education (negatively); and spouse's education and household production (both positively). The negative effect of own higher education on business ownership in the United States has been documented before (Blanchflower, 2004). In principle, this finding is consistent with the view that well educated specialists are less likely to pursue the path of independent business ownership than 'jacks of all trades' (Lazear, $2002,2004)$. The positive effect of spouse's education is to the best of our knowledge a novel ancillary result for the US, and consistent with Wong's (1986) findings for Hong Kong entrepreneurs. This might identify another conduit for knowledge spillovers. What is striking is the smaller set of significant covariates in columns I compared with the 'conventional' case where business ownership rates of married couples are assumed to be independent. Most notably, this includes the insignificance of children on female business ownership, in contrast to previous single equation estimates obtained earlier (see above) and previous authors (see Macpherson, 1988; Caputo and

\footnotetext{
${ }^{30}$ These effects are calculated by subsuming into the hypothesised change in spouse behaviour any interdependence between the decisions, and computing the usual formulae for marginal effects at the second stage holding values of the other covariates constant at the sample averages.
} 
Dolinsky, 1998; and Bruce, 1999). At the general level, it illustrates our earlier point that single equation reduced form estimates can be misleading. In the present context, failing to control for spouses' endogenous work patterns might show up through other manifestations of household structure, such as those relating to children. To understand business ownership patterns of married Americans, it appears necessary to take into account the occupational choices of spouses.

Next, we re-estimated model I by FIML. Using the 2SE starting values, the correlation coefficient was estimated to be -0.14 , with a standard error of $0.53 .^{31}$ Thus while this finding does not rule out assortative mating based on a range of observable criteria (e.g., ethnicity and education), it does not suggest that joint business ownership can be understood in terms of spouses sharing correlated unobserved preferences. To explore this matter further, we asked whether members of married couples share similar tastes that are embodied in the choice of similar industries or occupations prior to marriage. If future couples meet in jobs into which individuals purposively self-select, then large numbers of married couples should be observed working in the same industries and occupations before marriage compared with afterwards. We checked the proportions of married couples whose members both belong to the same 3-digit occupation and industry in 2003. The figures were $18.23 \%$ and $12.53 \%$, respectively. Among the couples who were unmarried 10 years before, however, the proportions were only $2.82 \%$ and $4.32 \%$, respectively. So far from marriage bringing people together from similar jobs, it seems that — in this sample at least — the occupational choices of spouses converge after they marry. Of course, this finding might also

\footnotetext{
${ }^{31}$ The numerical optimisation method of Broyden, Fletcher, Goldfarb and Shanno (BFGS) was used. The other FIML parameter estimates were all fairly similar to those reported using $2 \mathrm{SE}$ in Table 2, and so have been suppressed for brevity; they are available on request.
} 
capture age effects, as there is known to be greater variability in workers' job types when they are younger. But is does suggest that any unobserved correlated occupational choice effects are not strong enough to be identified in the data. And while it is possible that unobserved characteristics predispose members of some couples to choose similar occupations later in life, as noted above the FIML estimates cast doubt on this explanation.

Assortative mating is only one alternative explanation for interdependent business ownership decisions. Another is role model, or demonstration, effects. To test this, columns II of Table 2 augment the specification with the Role model variable described in Section 3.3. The final row of the table indicates significant negative effects from this variable. The implication is that having a spouse who has spent a long time as a business owner tends to deter individuals from trying it themselves. Taken literally, these findings are consistent with previous evidence that business ownership can have undesirable side effects on one's personal life (such as excessive work hours and relationship stress) that are reinforced by longer exposure to the phenomenon - and which deter spouses from trying it themselves (see, e.g., Williams, 2003; and Blanchflower, 2004). For instance, consider the effects on a person whose spouse had (a) been a business owner for a long time in the past, but (b) is very unlikely to be a business owner now. This is consistent with an outcome in which the wife was unwilling to abandon her business in the past, perhaps battling against the odds to keep it going, and being 'scarred' by the experience of ultimate business failure. The results in columns II suggest that this kind of battling experience deters the spouse from trying business ownership as well. ${ }^{32}$ Of course, this is no more than a way of visualising these findings, and is certainly not the only possible

\footnotetext{
${ }^{32} \mathrm{I}$ am grateful to Armin Falk for suggesting this interpretation.
} 
interpretation of these results.

Perhaps more centrally, the estimated coefficients on the role model dummy are inconsistent with the notion that this variable is conveying positive knowledge spillovers, since they are negative rather than positive. ${ }^{33}$ Thus we infer that spillovers are being conveyed through $\gamma_{1}$ and $\gamma_{2}$, which have both increased in magnitude, while remaining highly statistically significant (the corresponding marginal effects also increase, to 0.17 for men and 0.15 for women). The effects of most other variables remain similar to those reported in columns I. The principal exception is that for males, spouse's housework, poor health, and high school education become significantly positive, as does being black. ${ }^{34}$

Table 3 provide further augmentations of the econometric specification in order to test alternatives to the knowledge spillover story. ${ }^{35}$ Column III adds a measure of net household wealth to the specification. Household wealth rather than spouse's wealth was used, as the latter is unavailable in the PSID. (We acknowledge that this may constitute a limitation of this particular empirical test). 82 missing wealth values reduced the sample size to 4769. In order to reduce endogeneity problems (Hurst and Lusardi, 2004), whereby wealth at time $t$ could be an outcome of business success at time $t$, we constructed a wealth variable based on household assets (including home equity) two years before the sample date. ${ }^{36}$ Since negative values of wealth,

\footnotetext{
${ }^{33}$ See footnote 21. The negative sign is opposite to what Dunn and Holtz-Eakin (2000) found for the influence of parental self-employment on children's propensity to be selfemployed. It seems plausible that spouses convey the downsides of being a business owner more tangibly at the time they are business owners than parents do to offspring during the latter's childhood and adolescence.

${ }^{34}$ This particular empirical result appears to be a good example of how (single equation) reduced form estimates can lead to misleading interpretations compared to those obtained from a (simultaneous equation) structural model.

${ }^{35}$ Because few coefficient estimates change, only the key ones are included in this table to save space. Detailed results are available from the author on request.

${ }^{36}$ Because it is still possible that wealth is correlated with characteristics that affect the ownership decision, e.g., ability, we tried instrumenting wealth by lagged wealth,
} 
$x$, were observed in the data, values were transformed according to the formula $\ln (x+1)$ if $x \geq 0$ and $-\ln (-x+1)$ if $x<0$ (this is similar to the arc sine transformation). It is readily seen that the coefficients on the lagged wealth variable are numerically small, 'wrongly signed' for males, and statistically insignificant for women. At the same time, the $\gamma$ coefficients remain large in absolute value and statistically significant. These results are the opposite of what one would expect if interdependence in entrepreneurial choice merely reflected superior access to (a spouse's) resources. They are also consistent with recent research findings by Hurst and Lusardi (2004), who found little evidence that wealth drives participation in entrepreneurship. ${ }^{37}$

On the other hand, it is possible that business wealth is non-fungible so that business owner couples have a greater tendency to stay together when their marriages founder. Then once again, joint business ownership might occur for a reason other than knowledge spillovers. If this hypothesis is true, business owners should have life histories characterised by a lower incidence of divorce and separation than non-business owners. In fact, whereas $32.8 \%$ of male business owners in the sample had experienced more than one marriage ending in separation or divorce, only $26.5 \%$ of male non-business owners had. The corresponding figures for women were $36.5 \%$ and $26.7 \%$, respectively. This casts doubt on an explanation based on lower divorce rates associated with non-fungible assets.

In an attempt to identify risk effects separately from knowledge spillovers,

employment status, and other covariates used in Table 2. But this made no substantive difference to the results (available on request). In fact, any remaining endogeneity is likely to impart an upward bias to estimates of the entrepreneurship-wealth relationship; so any finding of an insignificant relationship might be taken as strong evidence that it is not empirically important.

${ }^{37}$ See also Bruce (1999), whose single equation probit analysis of married self-employed American women also found that a husband's participation dominates any wealth effects. Bruce estimated the marginal effect of male participation in self-employment on female self-employment participation to be 0.065 ; whereas the marginal effect in the female column of III is 0.14 . 
columns IV in Table 3 augment III with the dummy variable 'Same industry', which takes the value one if both members of a couple are working in the same 3-digit industry. All else equal, if risk-averse individuals face covariant risk and work in the same industry as their spouse, then a negative coefficient on 'Same industry' should be observed; the opposite should hold if individuals face diversifying risks. At the same time, the analysis of Section 2.3 suggests that $\gamma_{1}$ and $\gamma_{2}$ will increase (resp., decrease) in the presence of covariant (resp., diversifying) risk. In line with our expectations of covariant risk, the coefficients on the 'Same industry' dummy turn out to be negative. They are statistically significant only for males, while the $\gamma$ estimates (and marginal effects) are unchanged for men and actually drop for women. Hence controlling for risk in this way does not change our central findings. ${ }^{38}$ As a further check on the role of risk, we next included controls for relative risk aversion. Based on the survey methodology of Barsky et al (1997), these data were backed out of responses to PSID questions about the willingness of respondents to take jobs with different hypothetical income prospects, but the same non-monetary attributes as their current job. ${ }^{39}$ Data on an inverse measure of risk aversion ('risk tolerance') were distributed with the 1996 PSID, though not every respondent answered this question - or was participating in the PSID at that time. The net effect of using the risk aversion variable is to cut down our sample size by 1327 observations, with implicit selection of older respondents. Hence the results that follow should be treated with some caution. If attitudes to risk are important, one would expect a negative effect of risk aversion on the propensity

\footnotetext{
${ }^{38}$ The results were also very similar when 2 -digit industry data were used instead. Results are available from the authors on request.

${ }^{39}$ For details, see Ming-Ching Luoh and Frank Stafford's discussion at http://psidonline.isr.umich.edu/data/Documentation/Cbks/Supp/rt.html. Of course, one can object to the use of hypothetical questions to elicit risk preferences; but these are the best data available (and see Barsky et al, 1997, for a justification of their use).
} 
to be a business owner (Kihlstrom and Laffont, 1979). Columns V of Table 3 report the estimates; but these are found to be small and statistically insignificant, while the coefficient on 'Same industry' becomes insignificant for men as well as women. The relative lack of importance of risk attitudes (found also by Barsky et al, 1997) might explain the limited evidence of risk effects observed above.

Finally, Table 4 presents results derived using two alternative sample definitions: self-employment (columns VI) and non-partnerships (columns VII). The specification used for comparative purposes was that of columns II, because this conserves the largest sample size while retaining the generally significant 'Role model' covariate. In the first alternative sample definition, respondents were partitioned according to whether they were self-employed or employees in their main job. ${ }^{40}$ It has been argued that self-employment is not a coherent occupation at all, but resembles more of a legal classification (Dennis, 1996). It covers a wider range of vocations and professions than business ownership, including casual and seasonal jobs like window-cleaning as well as lucrative medical practices and management consultancies. Because it is more heterogeneous than business ownership, one might expect to find less interdependence between self-employment statuses of husbands and wives. In fact, columns VI reveal that the results are similar to those obtained directly using the business ownership classification. The results for women accord with previous findings of a positive effect on female selfemployment of having a self-employed husband (e.g., Bruce, 1999). The coefficients on the other variables were qualitatively similar to those reported in column II so are not repeated for brevity. In column VII, we exclude partnership businesses from the sample, resulting in a slight drop in sample

\footnotetext{
${ }^{40}$ A small number of cases who had mixed occupations were omitted from the sample. This did not materially affect the results.
} 
size to 4759 . This change in sample definition decreases the implied spillover received by women while barely affecting that received by men from column II. This may suggest that men receive spillovers irrespective of the organisational form of the business; while partnerships are an especially efficient conduit for transmitting spillovers to women.

\section{Conclusion}

This paper contributes to the growing literature on the determinants of entrepreneurship. We have proposed a framework of joint utility maximisation in which married people can exploit knowledge spillovers from their spouses. Married couples are an especially important group to analyse in the context of entrepreneurship because they make up the majority of business owners in America. We showed that individuals' choices of business ownership can in principle affect the choices of their spouses in a positive or negative fashion. Using a recent sample of PSID data, we found strong evidence of substantial positive interdependence between couples' business ownership choices. Furthermore, interdependence appears to play a major role in explaining patterns of business ownership in the United States. Further investigation suggests that knowledge spillovers are a reasonable interpretation of these findings; alternative explanations did not receive empirical support.

Because the value of spillovers can be expected to vary over time and different labour market conditions, caution should be exercised in the interpretation of our specific results. We also acknowledge the limitations of some of the empirical proxies used to test alternative explanations of interdependent business ownership. However, both our conceptual and empirical analyses suggest that neglecting interdependencies within couples may generate misleading results about the determinants of entrepreneurship; future 
research should take account of this. In particular, when researchers use samples of entrepreneurs containing numerous married couples, they should beware of endowing reduced form single equation logit/probit models with a structural interpretation. This issue may be of growing importance as the incidence of female business ownership in the United States continues to grow (Devine, 1994a, 1994b; Lombard, 2001).

We anticipate that the general methodology developed in this article may be usefully extended and applied to other occupations, especially ones in which there is abundant specialised information and knowledge that is not easily dispersed to 'outsiders'. Another application might be to countries where nepotism regulates entry to desirable jobs, and where being established in a desirable job opens doors to entry by spouses or close relatives, via a privately valuable (but possibly socially suboptimal) spillover. This raises the possibility that the scope of spillovers might extend beyond marriage, and encompass relatives and other kin, especially in societies where extended families are the norm. But even confining attention to married couples, there are plenty of ways that future research might incorporate and extend our work. One is to build interdependent occupational choice into household models of labour supply. Previous household models have sought to explain how couples allocate market production, household production and leisure; these choices might change if some occupations (such as entrepreneurship) offer easier opportunities for joint working and generate valuable spillovers that would otherwise be unattainable. A good empirical starting point would be to extend the model to analyse participation choices and their interface with occupational choices. More complicated econometric techniques might also be worth exploring, including the introduction of correlated random effects and lags to generate a simultaneous equation pro- 
bit dynamic panel data model. This does not exhaust the set of possible technical generalisations; our results should therefore probably be regarded as early steps in a longer empirical journey.

Finally, future work might also explore the effects of knowledge spillovers on business success: for example, company longevity or profitability. Previous research has found that determinants of entry into entrepreneurship generally differ from those of successful entrepreneurship, so extra insights might flow from an investigation of this issue; this particular problem might be tackled within a simultaneous tobit framework, for example. The prospect of connecting household participation in entrepreneurship with business success is an enticing one, that is likely to attract both academic and policy interest. 


\section{Appendix: Derivation of the FIML estimator}

From (13) and (14), write the covariance matrix of $u_{1}$ and $u_{2}$ as

$$
S=\left(\begin{array}{ll}
1 & \rho \\
\rho & 1
\end{array}\right),
$$

where $\rho$ is the correlation coefficient. Recall the definitions of $u_{1}^{*}$ and $u_{2}^{*}$ from (19). Using a standard result from the theory of multivariate normal distributions, $u_{1}^{*}$ and $u_{2}^{*}$ follow $N(0, \Sigma)$, where

$$
\begin{aligned}
\Sigma & =\left(\begin{array}{cc}
1 & -\gamma_{1} \\
-\gamma_{2} & 1
\end{array}\right)^{-1}\left(\begin{array}{ll}
1 & \rho \\
\rho & 1
\end{array}\right)\left[\left(\begin{array}{cc}
1 & -\gamma_{1} \\
-\gamma_{2} & 1
\end{array}\right)^{-1}\right]^{\prime} \\
& =\left(\begin{array}{ll}
\sigma_{1}^{2} & \rho^{*} \sigma_{1} \sigma_{2} \\
\rho^{*} \sigma_{1} \sigma_{2} & \sigma_{2}^{2}
\end{array}\right),
\end{aligned}
$$

where

$$
\begin{gathered}
\sigma_{1}^{2}:=\frac{1+2 \rho \gamma_{1}+\gamma_{1}^{2}}{\left(1-\gamma_{1} \gamma_{2}\right)^{2}} \quad, \quad \sigma_{2}^{2}:=\frac{1+2 \rho \gamma_{2}+\gamma_{2}^{2}}{\left(1-\gamma_{1} \gamma_{2}\right)^{2}} \\
\rho^{*}:=\frac{\gamma_{1}+\gamma_{2}+\rho\left(1+\gamma_{1} \gamma_{2}\right)}{\sqrt{\left(1+2 \rho \gamma_{1}+\gamma_{1}^{2}\right)\left(1+2 \rho \gamma_{2}+\gamma_{2}^{2}\right)}}
\end{gathered}
$$

The log-likelihood function has several terms, reflecting the probabilities of the four outcomes of: (a) joint participation $\left(z_{i 1}=z_{i 2}=1\right)$; (b) joint non-participation $\left(z_{i 1}=z_{i 2}=0\right)$; and (c) and (d) mixed participation $\left(z_{i 1}=\right.$ $1-z_{i 2}=0$ and $z_{i 2}=1-z_{i 1}=0$ ). The problem of estimating (15) and (17) subject to (20), (21) and (22) is akin to a bivariate probit problem, but with 
added structure. Hence the FIML log-likelihood function is

$$
\begin{aligned}
& \ln L\left(\alpha_{1}, \beta_{1}, \gamma_{1}, \alpha_{2}, \beta_{2}, \gamma_{2}, \rho\right)=-n \ln 2 \pi-\frac{1}{2} \sum_{i=1}^{n} \ln \left(1-\rho_{i}^{* 2}\right) \\
& +\sum_{i=1}^{n} \ln \left\{\int_{-\infty}^{w_{1}} \int_{-\infty}^{w_{2}} \exp \left[-\frac{1}{2}\left(\frac{u_{1}^{* 2}+u_{2}^{* 2}-2 \rho_{i}^{*} u_{1}^{*} u_{2}^{*}}{1-\rho_{i}^{* 2}}\right)\right] d u_{1}^{*} d u_{2}^{*}\right\}
\end{aligned}
$$

where

$$
\begin{aligned}
w_{1 i} & :=\frac{\left(2 z_{i 1}-1\right)\left(\alpha_{1}+\gamma_{1} \alpha_{2}\right)+\Xi_{i}^{\prime}\left(\beta_{1 \xi}+\gamma_{1} \beta_{2 \xi}\right)+\Lambda_{1 i}^{\prime} \beta_{1 \perp}+\Lambda_{2 i}^{\prime}\left(\gamma_{1} \beta_{2 \perp}\right)}{\sqrt{1+2 \rho \gamma_{1}+\gamma_{1}^{2}}} \\
w_{2 i} & :=\frac{\left(2 z_{i 2}-1\right)\left(\alpha_{2}+\gamma_{2} \alpha_{1}\right)+\Xi_{i}^{\prime}\left(\beta_{2 \xi}+\gamma_{2} \beta_{1 \xi}\right)+\Lambda_{2 i}^{\prime} \beta_{2 \perp}+\Lambda_{1 i}^{\prime}\left(\gamma_{2} \beta_{1 \perp}\right)}{\sqrt{1+2 \rho \gamma_{2}+\gamma_{2}^{2}}} \\
\rho_{i}^{*} & :=\frac{\left(2 z_{i 1}-1\right)\left(2 z_{i 2}-1\right)\left[\gamma_{1}+\gamma_{2}+\rho\left(1+\gamma_{1} \gamma_{2}\right)\right]}{\sqrt{1+2 \rho \gamma_{1}+\gamma_{1}^{2}} \sqrt{1+2 \rho \gamma_{2}+\gamma_{2}^{2}}}
\end{aligned}
$$




\section{References}

Acs, Z.J., Audretsch, D.B., Braunerhjelm, P. and B. Carlsson (2004) The missing link: The knowledge filter and entrepreneurship in endogenous growth, CEPR Discussion Paper No. 4783, www.cepr.org/pubs/dps/ DP4783.asp

Badgett, M. V. L and Folbre, N. (2003) Job gendering: Occupational choice and the marriage market, Industrial Relations, 42, 270-298.

Barsky, R. B.,Juster, F. T., Kimball, M. S. and M. D. Shapiro (1997), Preference parameters and behavioural heterogeneity: An experimental approach in the Health and Retirement Survey, Quarterly Journal of Economics, 112, pp. 537-79.

Bates, T. (1995) Self-employment entry across industry groups, Journal of Business Venturing, 10, pp. 143-56.

Berliant, M., Peng, S. K. and P. Wang (2002) Production externalities and urban configuration, Journal of Economic Theory, 104, pp. 275-303.

Blanchflower, D. G. (2004) Self-employment: More may not be better, Swedish Economic Policy Review, 11, pp. 15-74.

Blanchflower, D. G. and B. D. Meyer (1994) A longitudinal analysis of the young self-employed in Australia and the United States, Small Business Economics, 6, pp. 1-19.

Borjas, G. J. (1986) The self-employment experience of immigrants, Journal of Human Resources, 21, pp. 485-506.

Brock, W. A., and D. S. Evans (1986) The Economics of Small Businesses: Their Role and Regulation in the US Economy, Holmes and Meier, NY.

Bruce, D. (1999) Do husbands matter? Married women entering self-employment, Small Business Economics, 13, pp. 317-29.

Brush, C. (1992) Research on women business owners: past trends, a new 
perspective, and future directions, Entrepreneurship Theory 8 Practice, 16, pp. 6-30.

Cagetti, M. and M. De Nardi (2001) Entrepreneurship, default risk, bequests and wealth inequality, Mimeo, Department of Economics, University of Virginia, Charlottesville.

Caputo, R. K. and A. Dolinsky (1998) Women's choice to pursue selfemployment: The role of financial and human capital of household members, Journal of Small Business Management, 36, pp. 8-17.

Carter, M. R. (1997) Environment, technology, and the social articulation of risk in West African agriculture, Economic Development and Cultural Change, 45, 557-90.

Dennis, W. J. (1996) Self-employment: when nothing else is available? Journal of Labor Research, 17, pp. 645-61.

Devine, T. J. (1994a) Characteristics of self-employed women in the United States, Monthly Labor Review, 117, pp. 20-34.

Devine, T. J. (1994b) Changes in wage-and-salary returns to skill and the recent rise in female self-employment, American Economic Review, Papers and Procedings, 84, pp. 108-113.

Dunn, T. and D. Holtz-Eakin (2000) Financial capital, human capital and the transition to self-employment: evidence from intergenerational links, Journal of Labor Economics, 18, pp. 282-305.

Edwards, L. N. and E. Field-Hendrey (2002) Home-based work and women's labour force decisions, Journal of Labor Economics, 20, pp. 170-200.

Evans, D. S. and B. Jovanovic (1989) An estimated model of entrepreneurial choice under liquidity constraints, Journal of Political Economy, 97, pp. $808-27$.

Fairlie, R. W. (2004) Recent trends in ethnic and racial business ownership, 
Small Business Economics, 23, pp. 203-18.

Fairlie, R. W. and B. D. Meyer (1996) Ethnic and racial self-employment: differences and possible explanations, Journal of Human Resources, 31, pp. $757-93$.

Fuchs, V. R. (1982) Self-employment and labour-force participation of older males, Journal of Human Resources, 17, pp. 339-57.

Gentry, W. M. and R. G. Hubbard (2001) Entrepreneurship and household saving, Mimeo, Columbia University Business School, New York.

Gill, A. M. (1988) Choice of employment status and the wages of employees and the self-employed: some further evidence, Journal of Applied Econometrics, 3, pp. 229-34.

Holod, D. and R. R. Reed (2004) Regional spillovers, economic growth, and the effects of economic integration, Economics Letters, 85, pp. 35-42.

Hundley, G. (2001) Why women earn less than men in self-employment, Journal of Labor Research, 22, pp. 817-29.

Hurst, E. and A. Lusardi (2004) Liquidity constraints, household wealth, and entrepreneurship, Journal of Political Economy, 112, pp. 319-47.

Kalmijn, M. and H. Flap (2001) Assortative meeting and mating: Unintended consequences of organized settings partner choices, Social Forces, 79, pp. 1289-1312.

Keane, M. P. and K. I. Wolpin (1997) The career decisions of young men, Journal of Political Economy, 105, pp. 473-522.

Kihlstrom, R. E. and J. J. Laffont (1979) A general equilibrium entrepreneurial theory of firm formation based on risk aversion, Journal of Political Economy, 87, pp. 719-49.

Kooreman, P. (1994) Estimation of econometric models of some discrete games, Journal of Applied Econometrics, 9, pp. 255-68. 
Laband, D. N. and B. F. Lentz (1983) Like father, like son: Toward an economic theory of occupational following, Southern Economic Journal, 50, pp. $474-93$.

Lazear, E. P. (2002) Entrepreneurship, NBER Working Paper No. 9109, Cambridge, $M A$.

Lazear, E. P. (2004) Balanced skills and entrepreneurship, American Economic Review, Papers and Procedings, 94, pp. 208-11.

Lentz, B. F. and D. N. Laband (1990) Entrepreneurial success and occupational inheritance among proprietors, Canadian Journal of Economics, 23, pp. 563-79.

Lombard, K. V. (2001) Female self-employment and demand for flexible, non-standard work schedules, Economic Inquiry, 39, pp. 214-37.

Lundberg, S. (1988) Labour supply of husbands and wives: A simultaneous equations approach, Review of Economics and Statistics, 70, pp. 224-35.

Macpherson, D. A. (1988) Self-employment and married women, Economics Letters, 28, pp. 281-84.

Maddala, G. S. (1983) Limited Dependent and Qualitative Variables in Econometrics, New York: Cambridge University Press.

Moretti, E. (2004) Workers' education, spillovers, and productivity: Evidence from plant-level production functions, American Economic Review, 94, pp. 656-90.

Nakosteen, R. A., Westerlund, O. And M. A. Zimmer (2004) Marital matching and earnings: Evidence from the unmarried population in Sweden, Journal of Human Resources, 39, pp. 1033-44.

Parker, S. C. (2004) The Economics of Self-employment and Entrepreneurship, Cambridge University Press, Cambridge.

Perry, C. W. and H. S. Rosen (2004) The self-employed are less likely to have 
health insurance than wage earners. So what? in Holtz-Eakin, D. and H. S. Rosen (eds.) Public Policy and the Economics of Entrepreneurship, MIT Press, Cambridge, MA., pp. 23-57.

Praag, C. M. van (2005) Successful Entrepreneurship: Confronting Economic Theory with Empirical Evidence, London: Edward Elgar.

Rees, H. and A. Shah (1986) An empirical analysis of self-employment in the UK, Journal of Applied Econometrics, 1, pp. 95-108.

Reynolds, P. D., Storey, D. J. and P. Westhead (1994) Cross-national comparisons of the variation in new firm formation rates, Regional Studies, 28, pp. $443-56$.

Rosenzweig, M., and O. Stark (1989) Consumption smoothing, migration, and marriage: Evidence from rural India, Journal of Political Economy, 97, pp. 905-27.

Schuetze, H. (2004) Income splitting among the self-employed, Unpublished manuscript, University of Victoria, BC, Canada

Sena, V. (2004) The return of the Prince of Denmark: A survey on recent developments in the economics of innovation, Economic Journal, 114, pp. F312-F332.

Taniguchi, H. (2002) Determinants of womens entry into self-employment, Social Science Quarterly, 83, pp. 875-93.

Williams, D. R. (2003) Returns to education and experience in self-employment: Evidence from Germany, Journal of Applied Social Science Studies, 123, pp. 139-50.

Wong, Y-c. (1986) Entrepreneurship, marriage, and earnings, Review of Economics and Statistics, 68, pp. 693-99. 
Table 1: Summary statistics

\begin{tabular}{|c|c|c|c|c|}
\hline \multirow[t]{2}{*}{ Variable } & \multicolumn{2}{|c|}{ Males } & \multicolumn{2}{|c|}{ Females } \\
\hline & $\begin{array}{l}\text { Business } \\
\text { owners }\end{array}$ & $\begin{array}{l}\text { Non-business } \\
\text { owners }\end{array}$ & $\begin{array}{l}\text { Business } \\
\text { owners }\end{array}$ & $\begin{array}{l}\text { Non-business } \\
\text { owners }\end{array}$ \\
\hline \multicolumn{5}{|c|}{ A. Continuous variables } \\
\hline \multirow[t]{2}{*}{ Age } & 44.87 & 41.80 & 43.25 & 40.67 \\
\hline & $(10.00)$ & $(10.92)$ & $(9.53)$ & $(26.67)$ \\
\hline \multirow[t]{2}{*}{ Housework ${ }^{a}$} & 6.12 & 7.34 & 16.32 & 16.91 \\
\hline & $(6.50)$ & $(7.69)$ & $(9.57)$ & $(12.67)$ \\
\hline \multirow[t]{2}{*}{ No. children } & 1.12 & 1.13 & 1.10 & 1.13 \\
\hline & $(1.17)$ & $(1.20)$ & $(1.20)$ & $(1.19)$ \\
\hline \multirow[t]{2}{*}{ Role model ${ }^{b}$} & 3.05 & 0.83 & 3.72 & 0.56 \\
\hline & $(3.69)$ & $(2.02)$ & $(3.88)$ & $(1.47)$ \\
\hline \multirow[t]{2}{*}{ Wealth $2001^{c}$} & 10.77 & 8.58 & 11.26 & 8.69 \\
\hline & $(5.24)$ & $(6.35)$ & $(4.81)$ & $(6.32)$ \\
\hline \multirow[t]{2}{*}{$C R R A^{d}$} & 4.42 & 4.60 & 4.25 & 4.60 \\
\hline & $(2.14)$ & $(2.07)$ & $(2.09)$ & $(2.07)$ \\
\hline
\end{tabular}


Summary statistics, contd.

Variable

Males

Females

$\begin{array}{lllll}\text { Business } & \text { Non-business } & & \text { Business } & \text { Non-business } \\ \text { owners } & \text { owners } & & \text { owners } & \text { owners }\end{array}$

B. Dummy variables

\begin{tabular}{lllll} 
High school & 0.22 & 0.26 & 0.18 & 0.31 \\
College degree & 0.09 & 0.10 & 0.09 & 0.14 \\
Own poor health $^{e}$ & 0.003 & 0.03 & 0.003 & 0.02 \\
Black & 0.12 & 0.25 & 0.07 & 0.23 \\
Latino & 0.02 & 0.06 & 0.01 & 0.05 \\
Children $<6$ & 0.66 & 0.69 & 0.64 & 0.69 \\
Pa high school & 0.33 & 0.32 & 0.33 & 0.32 \\
Ma high school & 0.22 & 0.17 & 0.45 & 0.40 \\
North East & 0.15 & 0.15 & 0.14 & 0.15 \\
North Central & 0.24 & 0.25 & 0.28 & 0.25 \\
South & 0.38 & 0.38 & 0.29 & 0.41 \\
Medium urban & 0.25 & 0.25 & 0.21 & 0.26 \\
High urban & 0.38 & 0.40 & 0.35 & 0.40 \\
Same industry ${ }^{\prime}$ & 0.15 & 0.09 & 0.18 & 0.09 \\
& & & & \\
n & 659 & 4282 & 337 & 4604 \\
\hline \hline
\end{tabular}

Standard errors appear in parentheses for continuous variables. For dummy variables, standard errors are $\sqrt{p(1-p)}$, where $p$ is the mean.

${ }^{a}$ Average hours of housework per week.

${ }^{b}$ Length (in years) of spouse's most recent spell as a business owner

${ }^{c}$ Transformed dollar wealth in 2001 (see text).

${ }^{d}$ Coefficient of relative risk aversion (see text); $n$ here is 518, 3012, 277 and 3253

${ }^{e}$ Self-reported poor health status

${ }^{f}$ Whether both partners are currently working in the same industry 
Table 2: Parameter estimates of the simultaneous probit model of business ownership

\begin{tabular}{|c|c|c|c|c|}
\hline \multirow[t]{2}{*}{ Variable } & \multicolumn{2}{|r|}{$\mathbf{I}$} & \multicolumn{2}{|r|}{ II } \\
\hline & Males, $z_{1}^{*}$ & Females, $z_{2}^{*}$ & Males, $z_{1}^{*}$ & Females, $z_{2}^{*}$ \\
\hline \multirow[t]{2}{*}{ Males, $z_{1}^{*}$} & & $0.96^{* *}$ & & $1.60^{* *}$ \\
\hline & & $(0.26)$ & & $(0.44)$ \\
\hline \multirow[t]{2}{*}{ Females, $z_{2}^{*}$} & $0.65^{* *}$ & & $2.29^{* *}$ & \\
\hline & $(0.25)$ & & $(0.25)$ & \\
\hline \multirow[t]{2}{*}{ Linear age } & 0.07 & 0.09 & -0.08 & 12.71 \\
\hline & $(0.04)$ & $(5.91)$ & $(0.05)$ & $(12.35)$ \\
\hline \multirow[t]{2}{*}{ Quadratic age } & -0.03 & 0.07 & $0.11^{*}$ & 5.78 \\
\hline & $(0.03)$ & $(2.69)$ & $(0.05)$ & $(5.58)$ \\
\hline \multirow[t]{2}{*}{ High school (HS) } & 0.13 & -0.18 & 0.03 & -0.20 \\
\hline & $(0.09)$ & $(0.13)$ & $(0.21)$ & $(0.19)$ \\
\hline \multirow[t]{2}{*}{ Partner's HS } & 0.11 & -0.15 & $0.43^{*}$ & -0.29 \\
\hline & $(0.10)$ & $(0.14)$ & $(0.21)$ & $(0.22)$ \\
\hline \multirow[t]{2}{*}{ College (C) } & $-0.30^{*}$ & $-0.37^{* *}$ & $-0.86^{* *}$ & $-0.53^{* *}$ \\
\hline & $(0.13)$ & $(0.12)$ & $(0.24)$ & $(0.18)$ \\
\hline \multirow[t]{2}{*}{ Partner's C } & $0.32^{* *}$ & $0.40^{* *}$ & $0.60^{* *}$ & $0.52^{*}$ \\
\hline & $(0.09)$ & $(0.13)$ & $(0.19)$ & $(0.20)$ \\
\hline \multirow[t]{2}{*}{ Housework (HW) } & $-0.12^{* *}$ & -0.05 & -0.04 & -0.09 \\
\hline & $(0.04)$ & $(0.03)$ & $(0.09)$ & $(0.05)$ \\
\hline \multirow[t]{2}{*}{ Partner's HW } & $0.05^{*}$ & $0.10^{* *}$ & $0.10^{*}$ & $0.20^{*}$ \\
\hline & $(0.02)$ & $(0.07)$ & $(0.05)$ & $(0.10)$ \\
\hline \multirow[t]{2}{*}{ Poor health (PH) } & -0.42 & -0.47 & 0.72 & -0.57 \\
\hline & $(0.42)$ & $(0.53)$ & $(0.79)$ & $(0.99)$ \\
\hline \multirow[t]{2}{*}{ Partner's PH } & 0.18 & 0.04 & $2.24^{* *}$ & 0.56 \\
\hline & $(0.30)$ & ${ }^{46}(0.63)$ & $(0.59)$ & $(0.81)$ \\
\hline
\end{tabular}


Table 2 contd.

\begin{tabular}{|c|c|c|c|c|}
\hline \multirow[t]{2}{*}{ Variable } & \multicolumn{2}{|c|}{$\mathbf{I}$} & \multicolumn{2}{|c|}{ II } \\
\hline & Males, $z_{1}^{*}$ & Females, $z_{2}^{*}$ & Males, $z_{1}^{*}$ & Females, $z_{2}^{*}$ \\
\hline \multirow[t]{2}{*}{ Black } & -0.13 & -0.14 & $0.57^{*}$ & -0.09 \\
\hline & $(0.16)$ & $(0.19)$ & $(0.21)$ & $(0.21)$ \\
\hline \multirow[t]{2}{*}{ Latino } & -0.12 & -0.16 & 0.79 & -0.05 \\
\hline & $(0.24)$ & $(0.30)$ & $(0.41)$ & $(0.41)$ \\
\hline \multirow[t]{2}{*}{ Pa high school } & -0.02 & -0.07 & -0.06 & 0.00 \\
\hline & $(0.06)$ & $(0.07)$ & $(0.14)$ & $(0.12)$ \\
\hline \multirow[t]{2}{*}{ Ma high school } & -0.00 & -0.02 & 0.10 & -0.08 \\
\hline & $(0.06)$ & $(0.07)$ & $(0.13)$ & $(0.12)$ \\
\hline \multirow[t]{2}{*}{ Medium urban } & 0.11 & -0.17 & 0.27 & -0.25 \\
\hline & $(0.08)$ & $(0.09)$ & $(0.16)$ & $(0.14)$ \\
\hline \multirow[t]{2}{*}{ High urban } & 0.10 & $-0.16^{*}$ & $0.42^{* *}$ & -0.24 \\
\hline & $(0.08)$ & $(0.08)$ & $(0.15)$ & $(0.13)$ \\
\hline \multirow[t]{2}{*}{ No. children } & & -0.02 & & -0.05 \\
\hline & & $(0.05)$ & & $(0.07)$ \\
\hline \multirow[t]{2}{*}{ Child under 6} & & -0.06 & & -0.16 \\
\hline & & $(0.09)$ & & $(0.15)$ \\
\hline \multirow[t]{2}{*}{ Role model } & & & $-0.40^{* *}$ & $-0.27^{*}$ \\
\hline & & & $(0.07)$ & $(0.11)$ \\
\hline No. Obs. & 4851 & 4851 & 4851 & 4851 \\
\hline$-L L$ & 1823 & 1127 & 1527 & 1042 \\
\hline$\chi^{2}$ & $205^{* *}$ & $194^{* *}$ & $797^{* *}$ & $363^{* *}$ \\
\hline
\end{tabular}

Corrected standard errors are in parentheses. ${ }^{*} p$-value less than $0.05 ;{ }^{* *} p$-value less than 0.01. All specifications include intercepts and regional dummy variables (not reported for brevity); age and its sppare are orthogonal polynomials. Specification I is the base model; II includes role model effects (see text for definition). Coefficients and standard errors for the housework variables are scaled up by 10 ; those for linear and quadratic age by 100 . Estimator: 2 SE. 
Table 3: Parameter estimates of augmented specifications

\begin{tabular}{|c|c|c|c|c|c|c|}
\hline \multirow[t]{2}{*}{ Variable } & \multicolumn{2}{|c|}{ III } & \multicolumn{2}{|c|}{ IV } & \multicolumn{2}{|c|}{$\mathbf{V}$} \\
\hline & Males & Females & Males & Females & Males & Females \\
\hline \multirow[t]{2}{*}{ Males } & & $1.54^{* *}$ & & $1.38^{* *}$ & & $1.03^{* *}$ \\
\hline & & $(0.46)$ & & $(0.41)$ & & $(0.34)$ \\
\hline \multirow[t]{2}{*}{ Females } & $2.33^{* *}$ & & $2.33^{* *}$ & & $2.44^{* *}$ & \\
\hline & $(0.27)$ & & $(0.27)$ & & $(0.33)$ & \\
\hline \multirow[t]{2}{*}{ Role model } & $-0.41^{* *}$ & $-0.26^{*}$ & $-0.41^{* *}$ & $-0.22^{*}$ & $-0.45^{* *}$ & -0.14 \\
\hline & $(0.07)$ & $(0.11)$ & $(0.07)$ & $(0.10)$ & $(0.08)$ & $(0.08)$ \\
\hline \multirow[t]{2}{*}{ Wealth } & $-0.03^{*}$ & 0.00 & $-0.03^{*}$ & 0.00 & -0.02 & 0.00 \\
\hline & $(0.01)$ & $(0.01)$ & $(0.01)$ & $(0.01)$ & $(0.02)$ & $(0.02)$ \\
\hline \multirow[t]{2}{*}{ Same ind } & & & $-0.45^{*}$ & -0.09 & -0.18 & -0.11 \\
\hline & & & $(0.20)$ & $(0.19)$ & $(0.23)$ & $(0.18)$ \\
\hline \multirow[t]{2}{*}{ CRRA } & & & & & 0.04 & -0.03 \\
\hline & & & & & $(0.04)$ & $(0.02)$ \\
\hline No. Obs. & 4769 & 4769 & 4769 & 4769 & 3442 & 3442 \\
\hline$-L L$ & 1487 & 1016 & 1479 & 1012 & 1108 & 819 \\
\hline$\chi^{2}$ & $813^{* *}$ & $372^{* *}$ & $828^{* *}$ & $381^{* *}$ & $679^{* *}$ & $279^{* *}$ \\
\hline
\end{tabular}

Notes: Column III augments II with transformed wealth; IV augments III with the 'Same industry' dummy variable; and V augments IV with an imputed coefficient of relative risk aversion (CRRA). See text for details and Table 2 for asterisks. 
Table 4: Parameter estimates for alternative sample definitions

\begin{tabular}{|c|c|c|}
\hline Variable & VI & VII \\
\hline & Females & Females \\
\hline
\end{tabular}

\begin{tabular}{|c|c|c|c|c|}
\hline \multirow[t]{2}{*}{ Males } & & $1.66^{* *}$ & & $0.52^{*}$ \\
\hline & & $(0.54)$ & & $(0.27)$ \\
\hline \multirow[t]{2}{*}{ Females } & $2.86^{* *}$ & & $2.35^{* *}$ & \\
\hline & $(0.53)$ & & $(0.32)$ & \\
\hline No. Obs. & 4851 & 4851 & 4759 & 4759 \\
\hline$-L L$ & 1596 & 1302 & 1442 & 874 \\
\hline$\chi^{2}$ & $457^{* *}$ & $207^{* *}$ & $587^{* *}$ & $184^{* *}$ \\
\hline
\end{tabular}

Specification VI is as II but estimated for a self-employed rather than business owner sample; and VII is as II but estimated for a non-partnership business-owner sample. 